Article

\title{
Fast Catalytic Pyrolysis of Dilaurin in the Presence of Sodium Carbonate Alone or Combined with Alumina
}

\author{
Noyala Fonseca ${ }^{1}$, Aline Pereira ${ }^{1}$, Roger Fréty ${ }^{1,2}\left[\right.$ and Emerson Sales ${ }^{1,3, *(\mathbb{C})}$ \\ 1 Laboratory of Bioenergy and Catalysis (LABEC), Polytechnic School, Federal University of Bahia-UFBA, \\ Rua Aristides Novis, 2, 2nd floor, Federação, CEP 40.210-630 Salvador, Brazil; \\ noyala_nscf@hotmail.com (N.F.); alinepereira113@hotmail.com (A.P.); rfrety@ufba.br (R.F.) \\ 2 Department of Physical Chemistry, Chemistry Institute, Federal University of Bahia, IQ/UFBA, Ondina \\ University Campus, CEP 40.170-290 Salvador, Brazil \\ 3 Industrial Engineering Post-Graduation Program (PEI), Polytechnic School, Federal University of \\ Bahia-UFBA, Rua Aristides Novis, 2, 6th floor, Federação, CEP 40.210-630 Salvador, Brazil \\ * Correspondence: eas@ufba.br or andradesales.emerson@gmail.com; Tel.: +55-71-9-8887-8778
}

Received: 30 October 2019; Accepted: 25 November 2019; Published: 27 November 2019

\begin{abstract}
The objective of this work was to study the fast pyrolysis of a diglyceride intermediate compound during the conversion of triglycerides to fatty acids, esters and/or hydrocarbons. Dilaurin was selected as a model compound. Pyrolysis was conducted in a micro-pyrolyzer coupled to GC-MS equipment at 500,550 and $600{ }^{\circ} \mathrm{C}$ for $15 \mathrm{~s}$ in the presence of sodium carbonate $\left(\mathrm{Na}_{2} \mathrm{CO}_{3}\right)$ as the catalyst. Results were compared to pyrolysis data using $\gamma-\mathrm{Al}_{2} \mathrm{O}_{3}$ as a catalyst. At $600{ }^{\circ} \mathrm{C}$ with $\mathrm{Na}_{2} \mathrm{CO}_{3}$ almost total conversion of diglyceride was obtained, with the formation of $41.3 \%$ hydrocarbons (C3 to C13). In the same conditions using alumina as a catalyst $68.5 \%$ of hydrocarbons were obtained. $\mathrm{Na}_{2} \mathrm{CO}_{3}$ presented itself as an efficient feedstock modifier, allowing pre-cracking and partial deoxygenation of the load. The use of the $\mathrm{Na}_{2} \mathrm{CO}_{3}$ and $\gamma-\mathrm{Al}_{2} \mathrm{O}_{3}$ conjugated system in layers reduced the fatty acid content in the products, increasing both the reagent conversion and the hydrocarbon variety ( $\mathrm{C} 3$ to C23). This work suggests that the use of a double bed catalytic reactor is suitable for performing a deoxygenating pretreatment and producing hydrocarbons compatible with current liquid fuels, being potentially useful for more complex raw materials such as those from biomass treatments.
\end{abstract}

Keywords: fast catalytic pyrolysis; sodium carbonate; alumina; double bed micro reactor; dilaurin; deoxygenation

\section{Introduction}

Triglycerides, bio-constituents of plants, animals and microorganisms are raw materials exploited for food and energy purposes [1]. Biofuels derived from triglycerides are alternatives of social, environmental and economic interest, even more in remote areas, as they do not require significant adjustments in current engines technologies [2,3].

Thermochemical conversion processes, such as pyrolysis, a cracking path under an oxygen-free atmosphere and temperatures above $350^{\circ} \mathrm{C}$, with or without catalysts, are used to obtain biofuels chemically similar to those of fossil origin [4]. Fast pyrolysis is characterized by high heating rates, moderate temperatures and a short residence time; it allows for the maximization of liquid fraction and to determine the first compounds formed in the reaction system $[5,6]$. 
Thermal cracking of triglycerides gives, as primary products, fatty acids and a diglyceride. However, the latter has not been mentioned as one of the products formed under the fast pyrolysis conditions [7-9].

The acid content of bio-oils, caused by the presence of carboxylic acids and water content, is an important parameter for the use of biomass feedstock for biofuels production $[10,11]$. During pyrolysis of bio-oils, alkali metal carbonates, including sodium carbonate, were used to significantly decrease the oxygen content and the acidity of the products [12-14]. However, carbonates were generally used with complex feedstocks and not simple model molecules [15-18].

The present work aimed to study the products of fast catalytic pyrolysis of a model diglyceride, glycerol didodecanoate (dilaurin, D-12:0), in the presence of sodium carbonate, investigating its potential for dilaurin conversion and deoxygenation. The performance of sodium carbonate was compared to that of an alumina ( $\gamma$-alumina) catalyst, used in former studies of fatty compounds catalytic pyrolysis [5,7,8,19-21]. A synergic effect of both materials was observed by Imran et al. [22], using alumina-supported sodium carbonate catalyst for lignocellulosic biomass pyrolysis. In the present work, this synergetic effect was also studied, but using a double bed micro reactor with these two catalysts.

\section{Results and Discussion}

\subsection{Pyrolysis Temperature Effect}

Figure 1 presents the dilaurin molecule formula and suggests the main places where initial cracking may occur.

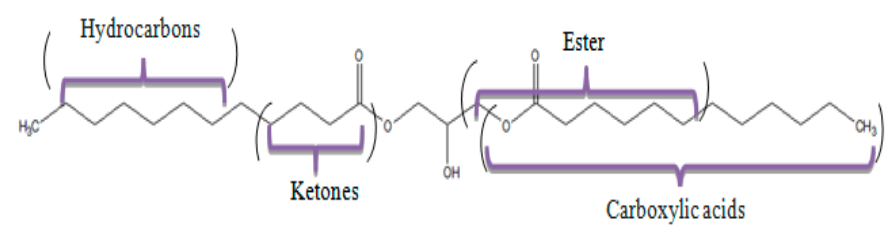

Figure 1. Dilaurin formula and possible potential positions of cracking during pyrolysis.

Figure 2 shows the pyrogram of dilaurin at $600{ }^{\circ} \mathrm{C}$, the best condition among the Group 1 experiments (for pure dilaurin, see Section 3), compared with the pyrogram obtained at $500{ }^{\circ} \mathrm{C}$. In this latter condition, dilaurin underwent only negligible transformation; on the other hand, at $600{ }^{\circ} \mathrm{C}$, a high conversion was noted and led to fully deoxygenated products such as hydrocarbons (C3 to C13). Less oxygenated molecules than dilaurin such as ketones, esters and fatty acids were also identified. 


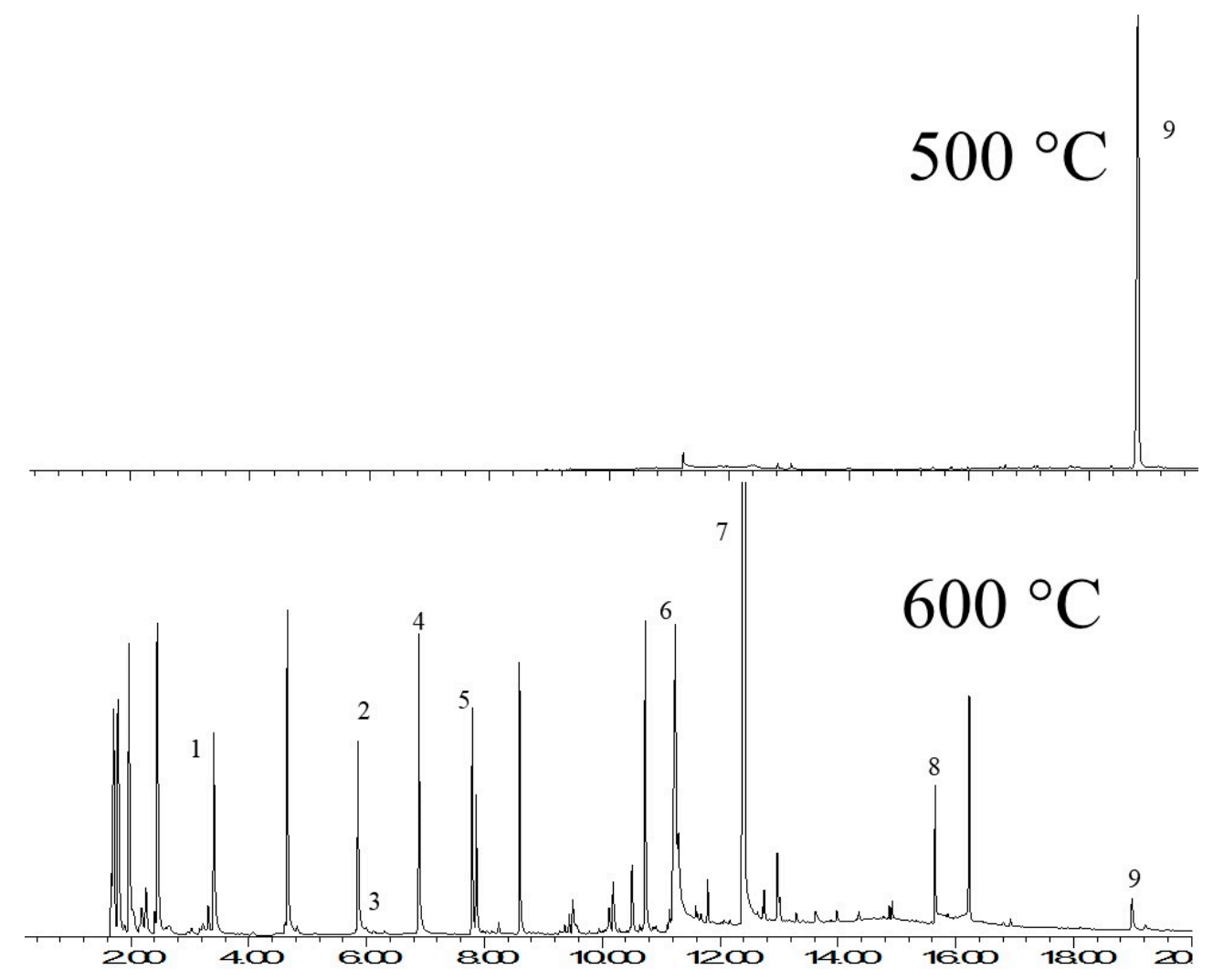

Figure 2. Dilaurin pyrograms at 500 and $600^{\circ} \mathrm{C}$ and identification of the main compounds: (1) 1-Heptene; (2) 1-Nonene; (3) n-Nonane; (4) 1-Decene; (5) 1-Undecene; (6) Dodecanoic acid; (7) Ethenyl Dodecanoate;

(8) 12-Tricosanone; (9) Dilaurin.

\subsection{Study of Thermocatalytic Effect}

In Group 2 experiments (for dilaurin adsorbed on sodium carbonate, see Section 3), the effect of the presence of $\mathrm{Na}_{2} \mathrm{CO}_{3}$ was studied: pyrograms after pyrolysis at $500{ }^{\circ} \mathrm{C}$ and $600{ }^{\circ} \mathrm{C}$ of D-12:0/ $\mathrm{Na}_{2} \mathrm{CO}_{3}$ are shown in Figure 3. At $500{ }^{\circ} \mathrm{C}, \mathrm{Na}_{2} \mathrm{CO}_{3}$ allowed a degradation of dilaurin $90 \%$ higher when compared to non-catalytic pyrolysis. At $550{ }^{\circ} \mathrm{C}$ the formation of trilaurin (T-12:0) was also observed. This fact contributed negatively to the hydrocarbons production, since T-12:0 could be considered a more complex substance to transform. Trilaurin may have been formed by the esterification reaction between the fatty acid formed in the reaction medium and the free hydroxyl group $(\mathrm{OH})$ of D-12:0. In the same Group 2 experiments, monoesters such as: ethenyl dodecanoate at $600{ }^{\circ} \mathrm{C}$, prop-2-en-1-yl decanoate at $600{ }^{\circ} \mathrm{C}$ and 1,3-dihydroxypropan-2-yl dodecanoate at $500{ }^{\circ} \mathrm{C}$ were identified. It was assumed that hydroxylated compounds such as ethenol and 2-propenol, although not isolated in the reaction medium, may have reacted with the fatty acids between the reacting area of the pyrolyser and the analytical part (transfer line at $320^{\circ} \mathrm{C}$ ), allowing their formation and transport.

With the temperature increase up to $600{ }^{\circ} \mathrm{C}$, lighter products were generated, with significant contribution of hydrocarbons, in relation to the thermally milder conditions, as observed in Figure 3 and Table 1. 


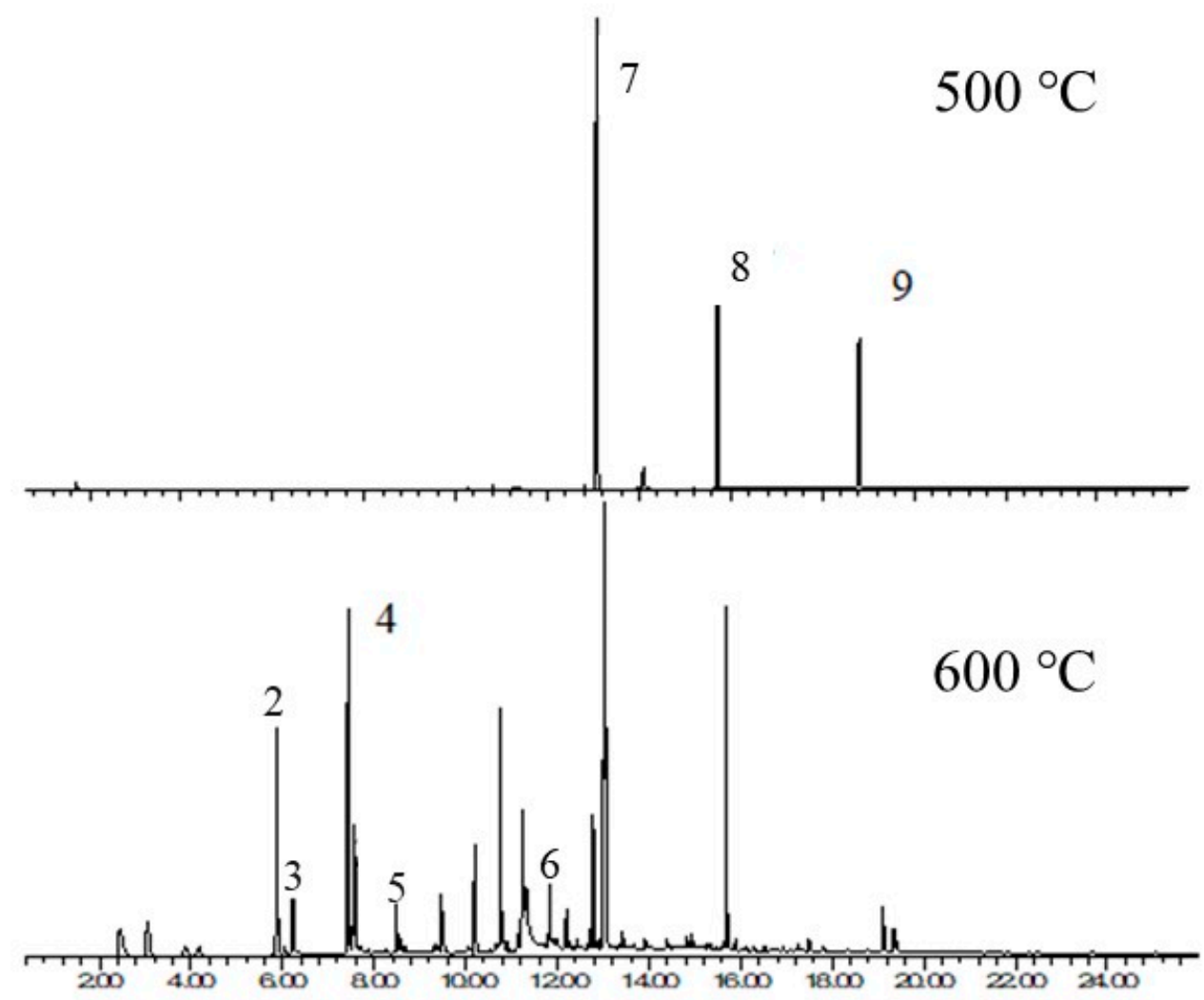

Figure 3. Pyrogram of dilaurin adsorbed on $\mathrm{Na}_{2} \mathrm{CO}_{3}(2 \mathrm{mg})$ at $500^{\circ} \mathrm{C}$ and $600^{\circ} \mathrm{C}$. Compounds identified: (2) 1-Nonene; (3) n-Nonane; (4) 1-Decene; (5) 1-Undecene; (6) Dodecanoic acid; (7) Ethenyl Dodecanoate; (8) 12-Tricosanone; (9) Dilaurin.

Comparing pyrolysis at $600{ }^{\circ} \mathrm{C}$ without or with sodium carbonate (Figures 2 and 3, respectively), there was a large reduction in the formation of dodecanoic acid (compound number 6) in the presence of carbonate, suggesting its ability to reduce the acidity of pyrolysis products.

Table 1. Distribution (\%) of compounds identified after pyrolysis of D-12:0 adsorbed on $\mathrm{Na}_{2} \mathrm{CO}_{3}$. Legend: (-) less than $0.5 \%$ of total area.

\begin{tabular}{cccc}
\hline Temperature $\left({ }^{\circ} \mathrm{C}\right)$ & $\mathbf{5 0 0}$ & $\mathbf{5 5 0}$ & $\mathbf{6 0 0}$ \\
\hline Hydrocarbons $(\%)$ & - & 3.7 & 41.3 \\
\hline Dilaurin/Trilaurin $(\%)$ & $17.6 /-$ & $9.0 / 18.9$ & $1.9 /-$ \\
\hline Ketones/Aldehydes $(\%)$ & $11.0 /-$ & $24.8 /-$ & $13.9 / 6.4$ \\
\hline Acids $(\%)$ & - & 1.2 & 7.4 \\
\hline
\end{tabular}

Deoxygenation of fatty acids, either by hydrogenation, decarbonylation or ketonization, produced water as a by-product [23,24], which could react with sodium carbonate by acid-base reaction and influence the transformation of oily and intermediate compounds. In the hydrolysis of canola oil to fatty acids, it was found that the presence of residual water inhibited the conversion of fatty acids to hydrocarbons [25].

Alteration of $\mathrm{Na}_{2} \mathrm{CO}_{3}$ by reacting with water, by thermal decomposition, or simply by the adsorptive effect of D-12:0, may have enabled the direct or indirect formation of sodium laurate and sodium carboxylate-like organic salts to decompose to form hydrocarbons [26] according to the equation: 


$$
\mathrm{C}_{\mathrm{n}} \mathrm{H}_{\mathrm{m}} \mathrm{COO}^{-} \mathrm{Na}^{+} \rightarrow \text { hydrocarbons }+\mathrm{CO}_{\mathrm{x}}+\mathrm{Na}_{2} \mathrm{O}
$$

Thermal pyrolysis of fatty acid salts under conditions close to that used in the present work $\left(450^{\circ} \mathrm{C}-750{ }^{\circ} \mathrm{C}\right.$; pyrolysis times between $20 \mathrm{~s}$ and $80 \mathrm{~s}$ ) were studied, and the presence of a homologous series of alkenes and alkanes as the main hydrocarbons as well as long chain ketones were detected [26].

The presence of esters and soaps, formed in situ, justified the use of inorganic sodium salts to reduce the acidity of the feedstock. The acidity reduction was also observed in the slow pyrolysis of vegetable oils at temperatures around $450{ }^{\circ} \mathrm{C}$, using $\mathrm{Na}_{2} \mathrm{CO}_{3}$ as the catalyst [12-14,27]. The formation of hydrocarbons, including alkanes, was confirmed in reactions having reactive molecules like the fatty acids formed by the initial degradation of triglycerides, due to the predominant effect of $\mathrm{Na}_{2} \mathrm{CO}_{3}$ basic properties. However, due to consecutive reactions and much longer reaction times than fast pyrolysis, intermediate conversion compounds such as esters and ketones were not clearly identified [23-27].

Once the effect of $\mathrm{Na}_{2} \mathrm{CO}_{3}$ on deoxygenation and quality improvement of pyrolysis products at $600{ }^{\circ} \mathrm{C}$ was confirmed, Group 3 experiments (dilaurin adsorbed on alumina or dilaurin adsorbed on sodium carbonate coated with an alumina layer, see Section 3) were performed. The corresponding pyrograms are compared in Figures 4 and 5, in order to verify the carbonate efficiency as a feedstock modifier, when used in conjunction with a reference catalyst, $\gamma$-alumina.

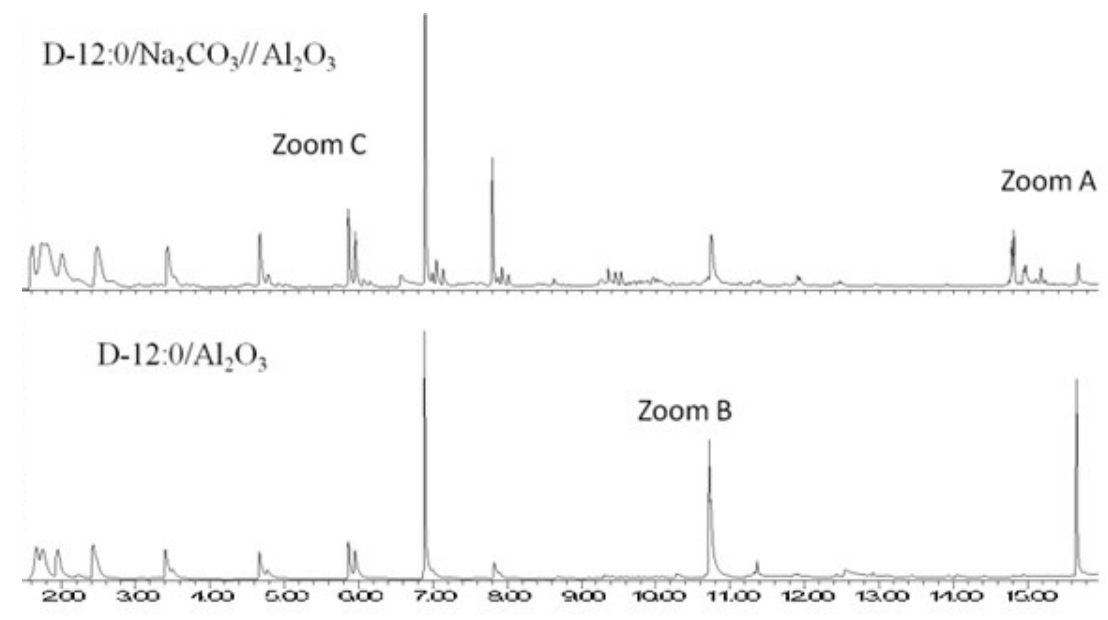

Figure 4. Pyrograms at $600{ }^{\circ} \mathrm{C}$ of dilaurin adsorbed on sodium carbonate covered with Alumina (D-12:0/ $\mathrm{Na}_{2} \mathrm{CO}_{3} / / \mathrm{Al}_{2} \mathrm{O}_{3}$ ) and dilaurin adsorbed on alumina (D-12:0/ $\mathrm{Al}_{2} \mathrm{O}_{3}$ ). For Zoom details see Figure 5.

In the case of all pyrolysis experiments performed with $\gamma$-alumina, D-12:0 was fully converted, and produced $68.5 \%$ of hydrocarbons ( $\mathrm{C} 3$ to $\mathrm{C} 13$ ). In the same conditions using $\mathrm{Na}_{2} \mathrm{CO}_{3}$, only $41.3 \%$ of hydrocarbons (also C 3 to C13) were obtained, confirming that $\gamma$-alumina is an efficient catalyst for the deoxygenation of oily compounds [7,8,19-21]. However, the nature of the products was not similar under the two conditions showed in Figures 4 and 5, nor their relative quantities. The use of the $\mathrm{Na}_{2} \mathrm{CO}_{3}$ and $\gamma-\mathrm{Al}_{2} \mathrm{O}_{3}$ conjugated system in layers (D-12:0/ $\mathrm{Na}_{2} \mathrm{CO}_{3} / / \mathrm{Al}_{2} \mathrm{O}_{3}$ ) exhibited a synergic effect, increasing both the quantity $(85.5 \%)$ and variety (C3 to $\mathrm{C} 23)$ of hydrocarbons.

Compound (13) (zoom (A), Figure 5), a symmetric ketone, 12-tricosanone, appeared to a greater extent under condition D-12:0/ $\mathrm{Al}_{2} \mathrm{O}_{3}$. Symmetrical ketones are known to result from the ketonic condensation of two identical carboxylic acids [23-25], in the present case dodecanoic acid (C12:0), one of the first cracking products of D-12:0. The higher intensity of the compound (13) in the products reflected lower conversion rates in cracking or deoxygenation of 12-tricosanone. This allowed us to say that the $\mathrm{Al}_{2} \mathrm{O}_{3}$ layer accelerated the conversion of 12-tricosanone and therefore decreased its amount among the products. 


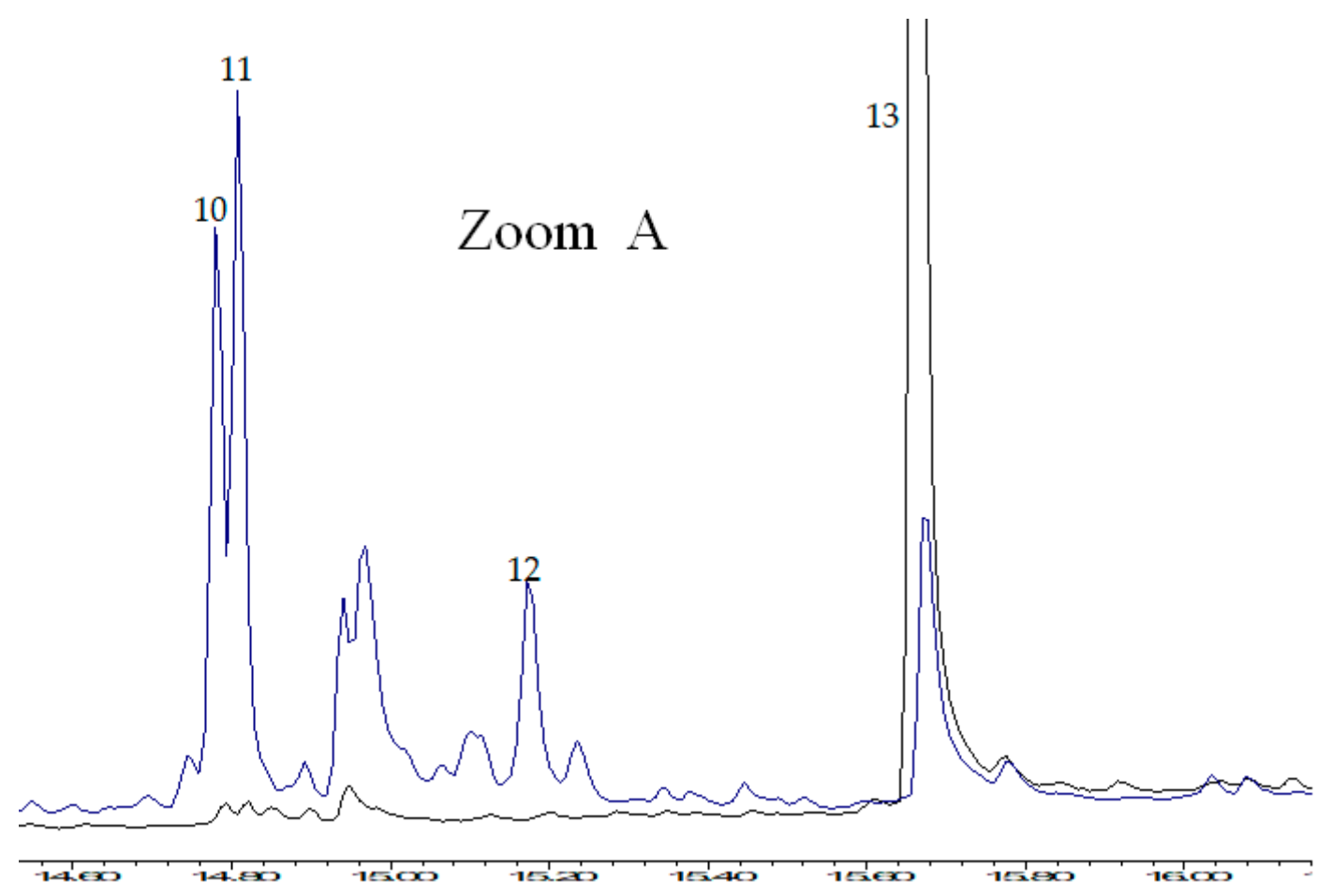

\section{Zoom B}

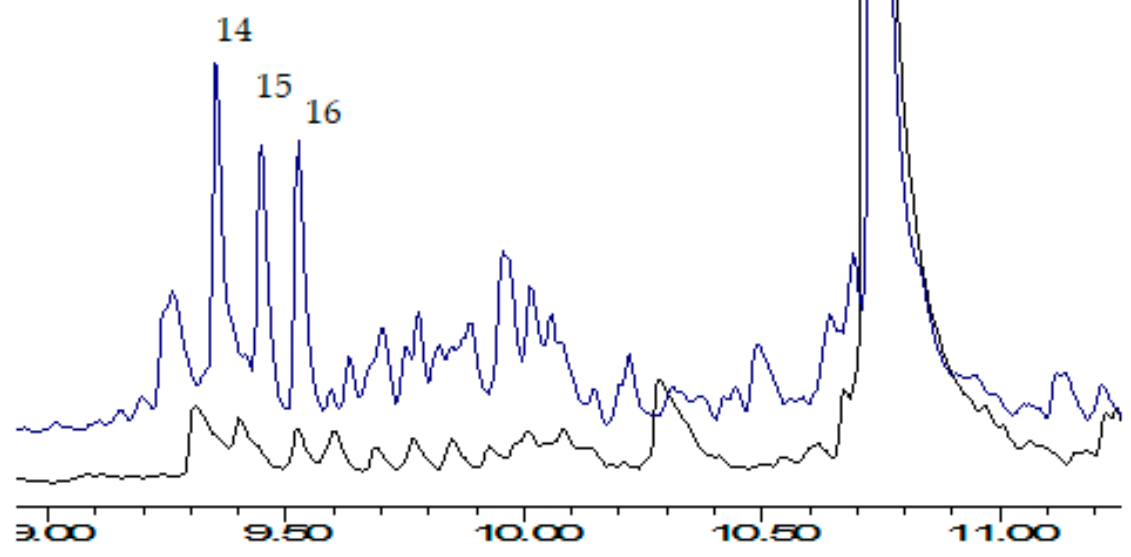

Figure 5. Cont. 


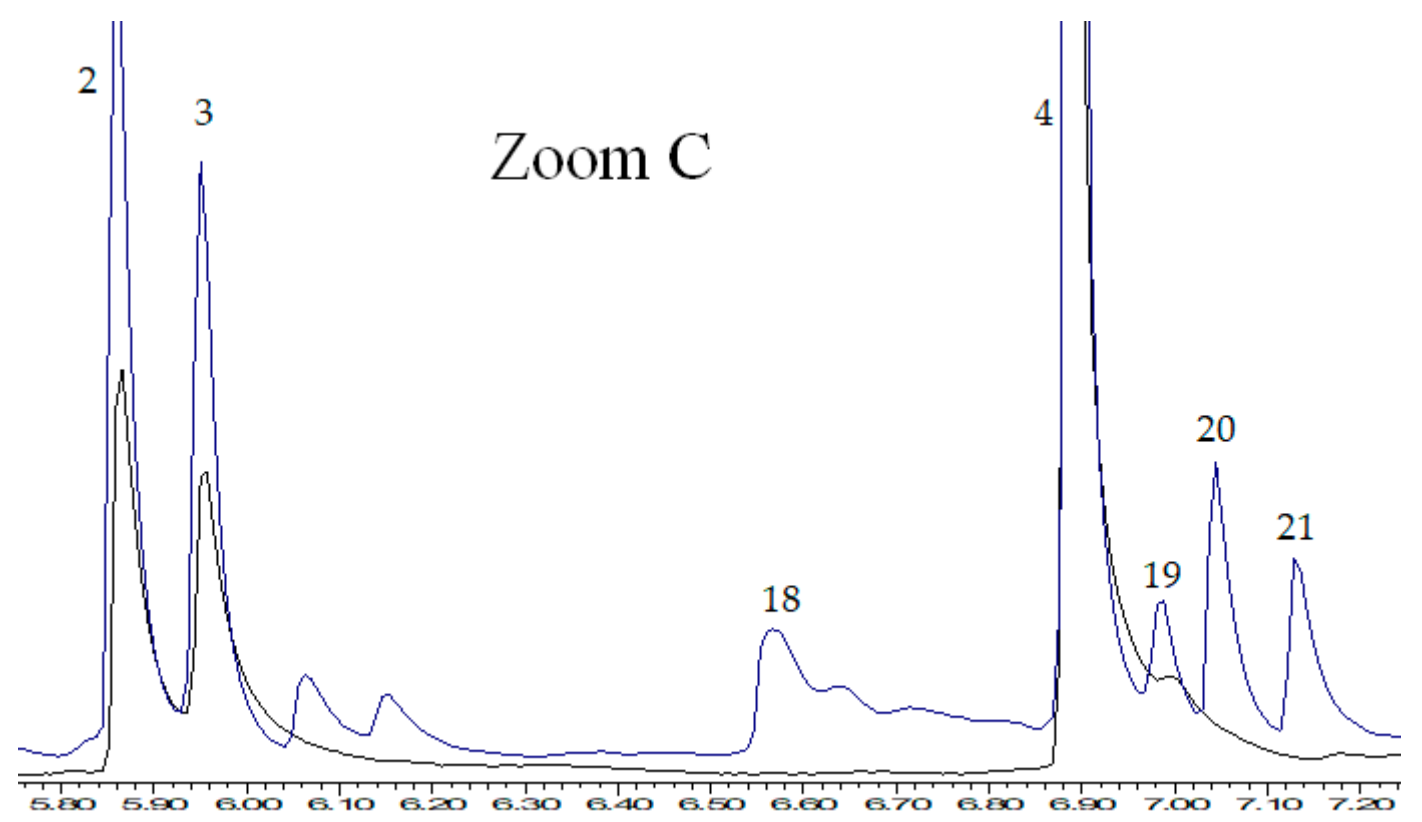

Figure 5. Details of Figure 4 pyrograms Zoom A, retention time from 14.6 to $16.0 \mathrm{~min}$, compounds identified: (10) 9-Tricosene; (11) 11-Tricosene; (12) 9-Octadecen-1-ol; (13) 12-Tricosanone; Zoom B, retention time from 9.0 to $11.2 \mathrm{~min}$, compounds identified: (14) 1-Tridecene; (15) 2-Tridecene; (16) 6-Tridecene; (17) 2-Tridecanone; Zoom C, retention time from 5.8 to $7.2 \mathrm{~min}$, compounds identified: (2) 1-Nonene; (3) n-Nonane; (4) 1-Decene; (18) 1-Heptyl-2-methylcyclopropane; (19) Decane; (20) (Z)-2-Decene; (21) (E)-2-Decene. Legend: Blue line: dilaurin adsorbed on sodium carbonate covered with Alumina (D-12:0/ $\mathrm{Na}_{2} \mathrm{CO}_{3} / / \mathrm{Al}_{2} \mathrm{O}_{3}$ ); Black line: dilaurin adsorbed on alumina (D-12:0/ $\left.\mathrm{Al}_{2} \mathrm{O}_{3}\right)$.

Products with a carbon chain containing 23 carbon atoms probably resulted from deoxygenation of 12-tricosanone by reduction / dehydration [23,25] and were present with greater abundance in the D-12:0/ $\mathrm{Na}_{2} \mathrm{CO}_{3} / / \mathrm{Al}_{2} \mathrm{O}_{3}$ experiment. As these products may have been the result of symmetric ketone transformation, it was suggested that sodium carbonate provided greater conversion of the fatty acid to ketone, and that alumina converted the latter to linear C23 hydrocarbons, methyl ketones (17) and lighter hydrocarbons. This hypothesis was supported by the discrete presence of the products (10), (11), (13), (14), (15) and (16) under condition D-12:0/ $\mathrm{Al}_{2} \mathrm{O}_{3}$, (Figure 5, zoom (A) and (B), black line) and the largest global area of light products, with 1-decene (4) being the most abundant (Figure 5, zoom (C)). These results were in good agreement with literature observations $[8,20,21]$.

Pyrolysis of D-12:0/ $\mathrm{Na}_{2} \mathrm{CO}_{3}$ (Figure 3) also produced light hydrocarbons such as 1-Heptene (1), 1-Nonene (2), n-Nonane (3), 1-Decene (4). After the addition of the alumina layer some 1-alkenes were isomerized, forming for example internal olefins such as (Z)-2-decene and (E)-2-decene (compounds 20 and 21, Figure 5, Zoom C). The acidic properties of alumina [28] are known to favor isomerization, cyclization [18] and eventually aromatization reactions [20] under such pyrolysis conditions.

\section{Materials and Methods}

Dilaurin (SUPELCO, batch LC 05732), sodium carbonate (PA, VETEC—99.5\%) and $\gamma$-alumina (Alcoa Aluminum S.A., Poços de Caldas-MG, Brazil, Code: A1, 0.013\% silica and 0.48\% sodium, BET surface area $71 \mathrm{~m}^{2} / \mathrm{g}$ ) were the main chemical compounds used in this work.

Three groups of experiments were performed; pyrolysis time was always $15 \mathrm{~s}$ and pyrolysis temperatures were 500,550 and $600{ }^{\circ} \mathrm{C}$, except for Group 3, performed only at $600{ }^{\circ} \mathrm{C}$.

Group 1-pyrolysis of pure dilaurin (D-12: 0);

Group 2-pyrolysis of dilaurin adsorbed on sodium carbonate (D-12:0/ $\mathrm{Na}_{2} \mathrm{CO}_{3}$ ); 
Group 3-(i) pyrolysis of dilaurin adsorbed on alumina (D-12:0/ $\mathrm{Al}_{2} \mathrm{O}_{3}$ ); (ii) pyrolysis of dilaurin adsorbed on sodium carbonate, coated with an alumina layer (D-12:0/ $\mathrm{Na}_{2} \mathrm{CO}_{3} / / \mathrm{Al}_{2} \mathrm{O}_{3}$ ).

For pyrolysis reactions, dilaurin was used pure or after its "impregnation" on the surface of both catalysts. The powdered catalysts were hand mixed according to a ratio of 10/1 (catalyst mass/dilaurin mass) by stirring and friction with a glass rod, first at laboratory temperature and then at $95{ }^{\circ} \mathrm{C}$, a temperature higher than the melting point of dilaurin, and lower than its flash point, in order to promote the diffusion of the liquid molecules on the total surface of the catalysts. The prepared samples were referred to as D-12:0/catalyst, "catalyst" being sodium carbonate or alumina.

Similar to a preceding study [29], pyrolysis reactions were done using a Frontier Laboratories LTD Multi-Shot Pyrolyzer (Koriyama, Fukushima, JAPAN) Model EGA / PY-3030D connected online to a gas chromatograph coupled to a mass spectrometer Agilent GC-MS 5799A (New Castle, DE, USA). A Frontier Laboratories UA5-30M-0.25F GC column was used ( $30 \mathrm{~m}$ length, $0.25 \mathrm{~mm}$ diameter, $5 \%$ diphenyl stationary phase and $95 \%$ dimethylpolysiloxane, $0.25 \mu \mathrm{m}$ film thickness), subjected to an initial temperature of $40{ }^{\circ} \mathrm{C}$ for $2 \mathrm{~min}$, followed by a heating ramp at a rate of $20^{\circ} \mathrm{C} / \mathrm{min}$ up to $320^{\circ} \mathrm{C}$, with the temperature maintained for 10 more minutes. The MS ion source and the interface pyrolyzer/injector temperatures were both fixed at $320^{\circ} \mathrm{C}$. Values of $\mathrm{m} / \mathrm{z}$ were set in the range of 40 to 400, in scan mode.

A mass of $2 \mathrm{mg}$ of the D12:0/catalyst sample or $0.2 \mathrm{mg}$ of pure dilaurin was inserted into a deactivated stainless-steel sample holder and prior to the pyrolysis experiments. In Group 3 (ii) experiments, a $5 \mathrm{mg}$ layer of $\gamma$-alumina was placed over the $\mathrm{D} 12: 0 / \mathrm{Na}_{2} \mathrm{CO}_{3}$ layer and covered with a thin layer of quartz wool. The sample holder was then placed in the equipment under helium flow for purging, and the micro-pyrolyzer furnace was preheated to the desired pyrolysis temperature $\left(500,550\right.$ and $600^{\circ} \mathrm{C}$ ). After stabilization, the sample holder was dropped into the hot zone where it remained for $15 \mathrm{~s}$ at the chosen temperature. An aliquot of the gas phase was automatically inserted into the GC/MS equipment.

For the analysis of the products, the chromatographic peaks with an area lower than $0.5 \%$ of the total area were neglected. The peaks were identified using the NIST Database, and only those products with an identification probability greater than $70 \%$ were considered. The other products were classified as not identified (NI). The estimated compositions after pyrolysis were calculated dividing the peak areas of the specific products by the total area of the non-neglected peaks, including both the non-identified products and the remaining reactant, dilaurin.

\section{Conclusions}

Sodium carbonate allowed for the total conversion of dilaurin during the fast pyrolysis at $600{ }^{\circ} \mathrm{C}$, reduced the amount of dodecanoic acid formed when compared to thermal pyrolysis, suggesting its ability to reduce the acidity of pyrolysis products, and led to the formation of $41.3 \%$ hydrocarbons (C3 to C13). Therefore, it could be considered as a pre-catalyst for the pyrolysis process, allowing pre-cracking and partial deoxygenation of complex feedstocks such as bio-oils, making them less aggressive.

In the case of pyrolysis experiments performed at $600{ }^{\circ} \mathrm{C}$ with $\gamma$-alumina, D-12:0 was also fully converted, and produced $68.5 \%$ of the hydrocarbons (also $\mathrm{C} 3$ to $\mathrm{C} 13$ ). The use of the $\mathrm{Na}_{2} \mathrm{CO}_{3}$ and $\gamma-\mathrm{Al}_{2} \mathrm{O}_{3}$ conjugated system in layers proved to be effective for the degradation of a complex oxygenated molecule, dilaurin, and increased both the quantity (85.5\%) and variety (C3 to $\mathrm{C} 23$ ) of hydrocarbons similar to those from current liquid fuels. The present results suggest that the double bed catalyst configuration can be useful for transforming more complex raw feedstocks such as those issued from biomass treatments into "green" fuels.

Author Contributions: Conceptualization, N.F. and A.P.; methodology, N.F., A.P., R.F. and E.S.; validation, N.F., R.F. and E.S.; formal analysis N.F., R.F. and E.S.; investigation, N.F., A.P., R.F. and E.S.; resources, R.F. and E.S.; data curation, N.F., R.F. and E.S.; writing—original draft preparation, N.F., A.P., R.F. and E.S.; writing一review and editing, N.F., R.F. and E.S.; supervision, R.F. and E.S.; project administration, E.S.; funding acquisition, E.S. 
Funding: This research was funded by CAPES (Coordenação de Aperfeiçoamento de Pessoal de Nível Superior) and $\mathrm{CNPq}$ (Conselho Nacional de Desenvolvimento Científico eTecnológico).

Acknowledgments: The authors are grateful to CNPq, CAPES, PEI (Programa de Engenharia Industrial) and to the Coordination Chemistry Research Group-GPQC, Institute of Chemistry, Federal University of Bahia, Brazil.

Conflicts of Interest: The authors declare no conflicts of interest.

\section{References}

1. Cherubini, F. The biorefinery concept: Using biomass instead of oil for producing energy and chemicals. Energy Convers. Manag. 2010, 51, 1412-1421. [CrossRef]

2. Cremonez, P.A.; Feroldi, M.; Feiden, A.; Teleken, J.G.; Gris, D.J.; Dieter, J.; De Rossi, E.; Antonelli, J. Current scenario and prospects of use of liquid biofuels in South America. Renew. Sustain. Energy Rev. 2015, 43, 352-362. [CrossRef]

3. Lossau, S.; Fischer, G.; Tramberend, S.; Van Velthuizen, H.; Kleinschmit, B.; Schomäcker, R.; Schomaecker, R. Brazil's current and future land balances: Is there residual land for bioenergy production? Biomass Bioenergy 2015, 81, 452-461. [CrossRef]

4. Maher, K.; Bressler, D. Pyrolysis of triglyceride materials for the production of renewable fuels and chemicals. Bioresour. Technol. 2007, 98, 2351-2368. [CrossRef] [PubMed]

5. Frety, R.; Pacheco, J.G.; Santos, M.R.; Padilha, J.F.; Azevedo, A.F.; Brandão, S.T.; Pontes, L.A. Flash pyrolysis of model compounds adsorbed on catalyst surface: A method for screening catalysts for cracking of fatty molecules. J. Anal. Appl. Pyrolysis 2014, 109, 56-64. [CrossRef]

6. Chagas, B.M.; Dorado, C.; Serapiglia, M.J.; Mullen, C.A.; Boateng, A.A.; Melo, M.A.; Ataíde, C.H. Catalytic pyrolysis-GC/MS of Spirulina: Evaluation of a highly proteinaceous biomass source for production of fuels and chemicals. Fuel 2016, 179, 124-134. [CrossRef]

7. Vonghia, E.; Boocock, D.G.B.; Konar, S.K.; Leung, A. Pathways for the Deoxygenation of Triglycerides to Aliphatic Hydrocarbons over Activated Alumina. Energy Fuels 1995, 9, 1090-1096. [CrossRef]

8. Leung, A.; Boocock, D.G. Pathway for the catalytic conversion of carboxylic acids to hydrocarbons over activated alumina. Energy Fuels 1995, 9, 913-920. [CrossRef]

9. Seifi, H.; Sadrameli, S.M. Bound cleavage at carboxyl group-glycerol backbone position in thermal cracking of the triglycerides in sun flower oil. J. Anal. Appl. Pyrolysis 2016, 121, 1-10. [CrossRef]

10. Zhang, Q.; Zhang, L.; Wang, T.; Xu, Y.; Zhang, Q.; Ma, L.; He, M.; Li, K. Upgrading of Bio-oil by Removing Carboxylic Acids in Supercritical Ethanol. Energy Procedia 2014, 61, 1033-1036. [CrossRef]

11. Shakya, R.; Adhikari, S.; Mahadevan, R.; Hassan, E.B.; Dempster, T.A. Catalytic upgrading of bio-oil produced from hydrothermal liquefaction of Nannochloropsis sp. Bioresour. Technol. 2018, 252, 28-36. [CrossRef] [PubMed]

12. Santos, M.; Lourenço, R.; De Abreu, D.; Pereira, A.; De Castro, D.; Pereira, M.; Almeida, H.; Mâncio, A.; Lhamas, D.; Da Mota, S.; et al. Gasoline-like hydrocarbons by catalytic cracking of soap phase residue of neutralization process of palm oil ( Elaeis guineensis Jacq). J. Taiwan Inst. Chem. Eng. 2017, 71, 106-119. [CrossRef]

13. Mancio, A.; Da Costa, K.; Ferreira, C.; Santos, M.; Lhamas, D.; Da Mota, S.; Leão, R.; De Souza, R.; Araújo, M.; Borges, L.; et al. Thermal Catalytic Cracking of Crude Palm Oil at Pilot Scale: Effect of the Percentage of Na2CO3 on the Quality of Biofuels. Crop. Prod. 2016, 91, 32-43. [CrossRef]

14. Mâncio, A.; Da Costa, K.; Ferreira, C.; Santos, M.; Lhamas, D.; Da Mota, S.; Leão, R.; De Souza, R.; Araújo, M.; Borges, L.; et al. Process analysis of physico chemical properties and chemical composition of organic liquid products obtained by thermochemical conversion of palm oil. J. Anal. Appl. Pyrolysis 2017, 123, $284-295$. [CrossRef]

15. Smets, K.; Roukaerts, A.; Czech, J.; Reggers, G.; Schreurs, S.; Carleer, R.; Yperman, J. Slow catalytic pyrolysis of rapeseed cake: Product yield and characterization of the pyrolysis liquid. J. Biomass Bioenergy 2013, 57, 180-190. [CrossRef]

16. Long, F.; Li, F.; Zhai, Q.; Wang, F.; Xu, J.; Feng, L.; Fanglin, L.; Qiaolong, Z. Thermochemical conversion of waste acidic oil into hydrocarbon products over basic composite catalysts. J. Clean. Prod. 2019, 234, 105-112. [CrossRef] 
17. Imran, A.; Bramer, E.A.; Seshan, K.; Brem, G. Catalytic flash pyrolysis of oil-impregnated-wood and jatropha cake using sodium-based catalysts. J. Anal. Appl. Pyrolysis 2016, 117, 236-246. [CrossRef]

18. Abdelfattah, M.S.H.; Abu-Elyazeed, O.S.M.; El Mawla, E.A.; Abdelazeem, M.A. On biodiesels from castor raw oil using catalytic pyrolysis. Energy 2018, 143, 950-960. [CrossRef]

19. Dos Anjos, J.R.; Gonzales, W.A.; Lam, Y.L.; Fréty, R. Catalytic decomposition of vegetable oil. Appl. Catal. 1983, 5, 299-308. [CrossRef]

20. Santos, M.R.; Arias, S.; Padilha, J.F.; Carneiro, M.C.N.; Sales, E.A.; Pacheco, J.G.A.; Fréty, R. Catalytic cracking of palmitic and oleic acids pre-adsorbed on $\gamma$-alumina Catal. Today 2019, in press. [CrossRef]

21. Billaud, F.; Minh, A.T.; Lozano, P.; Pioch, D. Catalytic cracking of octanoic acid. J. Anal. Appl. Pyrolysis 2001, 58-59, 605-616. [CrossRef]

22. Imran, A.; Bramer, E.A.; Seshan, K.; Brem, G. High quality bio-oil from catalytic flash pyrolysis of lignocellulosic biomass over alumina-supported sodium carbonate. Fuel Process. Technol. 2014, 127, 72-79. [CrossRef]

23. Renz, M. Ketonization of carboxylic acids by decarboxylation: Mechanism and scope. Eur. J. Org. Chem. 2005, 6, 979-988. [CrossRef]

24. Meneghetti, S.M.P.; Meneghetti, M.R.; Wolf, C.R.; Suarez, P.A.Z. Transformação de triglicerídeos em combustíveis, materiais poliméricos e insumos químicos: Algumas aplicações da catálise na oleoquímica. Química Nova 2007, 30, 667-676. [CrossRef]

25. Kumar, R.; Enjamuri, N.; Shah, S.; Al-Fatesh, A.S.; Bravo-Suárez, J.J.; Chowdhury, B. Ketonization of oxygenated hydrocarbons on metal oxide-based catalysts. Catal. Today 2018, 302, 16-49. [CrossRef]

26. Lappi, H.; Alén, R. Pyrolysis of vegetable oil soaps-Palm, olive, rapeseed and castor oils. J. Anal. Appl. Pyrolysis 2011, 91, 154-158. [CrossRef]

27. Almeida, H.D.S.; Corrêa, O.; Eid, J.; Ribeiro, H.; De Castro, D.; Pereira, M.; Pereira, L.; Aâncio, A.D.A.; Santos, M.; Da Mota, S.; et al. Performance of thermochemical conversion of fat oils, and grease into kerosene-like hydrocarbons in different production scales J. Anal. Appl. Pyrolysis 2016, 120, 126-143. [CrossRef]

28. Mukhambetov, I.N.; Egorova, S.R.; Mukhamed'Yarova, A.N.; Lamberov, A.A. Hydrothermal modification of the alumina catalyst for the skeletal isomerization of n-butenes. Appl. Catal. AGen. 2018, 554, 64-70. [CrossRef]

29. Freitas, C.; Pereira, M.; Souza, D.; Fonseca, N.; Sales, E.; Frety, R.; Felix, C.; Azevedo, A.; Brandao, S. Thermal and Catalytic Pyrolysis of Dodecanoic Acid on SAPO-5 and Al-MCM-41. Catalysts 2019, 9, 418. [CrossRef] 